\title{
Students' Mistakes and Misconceptions on the Subject of Conics
}

\author{
Eyus Sudihartinih and Tia Purniati
}

\author{
Department of Mathematics Education, Universitas Pendidikan Indonesia, Bandung, \\ Indonesia \\ eyuss84@upi.edu
}

First draft received: 7 August 2019 Date Accepted: 15 Dec 2019 Final proof received: 28 Feb 2020

\begin{abstract}
The purpose of this study is to determine the levels of geometric thinking, mistakes, and misconceptions of students on the concept of conics. This study was conducted on 91 students in the first semester in 2017 at one of the universities in Indonesia. Data were collected using written tests, interviews, and documentation. From the test results, the students' answers were divided into correct and incorrect solutions. Interviews and documentation were used to analyze level of geometric thinking nd student misconception. As a result, the misconceptions found were (1) the students could not determine the two possible simple equations, (2) the students could not determine the description of a simple parabola equation, (3) the students could not determine the conics equation, (4) the students could not prove the length of the latus rectum of an ellipse, (5) the students could not determine a simple equation of asymptote of hyperbola, while its vertices point were known, and (6) the students could not determine the equations of hyperbola focus and the difference between the length of the radius of the focus was known. Students who experienced mistakes and misconceptions were still at the first level of the van Hiele geometric thinking model.

Keywords: conics; geometry; mathematics education; misconception

To cite this paper (in APA style):

Sudihartinih, E., \& Purniati, T. (2019). Students' mistakes and misconceptions on the subject of conics. Indonesian Journal of Education, 12(2), doi: 10.17509/ije.v12i2.19130
\end{abstract}

\section{INTRODUCTION}

Geometry plays an important role in learning at the elementary, middle, and high levels of the curriculum in the world. Geometry also plays an important role in applied science, technology, and production and is proven to be the best tool for developing logical thinking (Chernysheva et al., 1986). The purpose of geometry is for students to have confidence in their mathematical abilities, to be good problem solvers, to communicate and reason mathematically (Bobango in Ramlan, 2016: 63). Geometry is a rich source of visualization for understanding the concept of algebra, calculus, and statistics. Knowledge of geometry remains a prerequisite for study in fields such as astronomy, art, mechanical drawing, physics, chemistry, biology, and geology (Luneta, 2013). Jones (2002) stated that geometry contributed to helping students develop visualization skills, problem-solving skills, conjectures, deductive reasoning, critical thinking, intuition, perspective, logical arguments, and evidence. Fichte (in Wood 2012) believed that learning geometry could develop rational and logical thinking. The experience of learning geometry influences one's ability to work in geometry (Hiele, 1959/1985). In order for students to get a good geometry learning experience, the teacher should know the level of development of students' thinking, so that they can decide the learning that will be conducted because two people who are at different levels do not understand each other (Hiele, 1959/1985).

The students' planning on quantitative majors need extensive instruction, among others, in analytical geometry (Mathematics Standards Study Group, 2004: 7). In analytical geometry, there is an interesting concept that is the concept of conic in which there are concepts of parabola, hyperbola, ellipse, and circle (the circle has been studied before). The concept of conics has been widely studied (Ayoub, 2007; Kung, 2003; Motz \& Weafer, 1994; Nhi, Tinh, \& Phuong, 2014; Sari, 2016; Qudtsi, Setiawan, \& Lestari, 2015; Venters, 1992). So, this concept is important to learn both at school and university.

Peng-yee and Chong-keang (1986) surveyed geometry teaching in Southeast Asia, some of which resulted in attempts to introduce more geometry to schools that had failed. Del Grande (in Gal \& Linchevski, 2010) claimed that geometry was difficult for students because the subject was deductive, and it required good spatial ability. The study by Luneta (2015) also noted that geometry was difficult to teach 
and also to be studied (for example analytical geometry). Many reported misconceptions and mistakes of students in geometry learning (Biber, Tuna, Korkmaz, 2013; Kim \& Luneta, 2015; Makhubele, Nkhoma, \& Luneta, K. (2015); Mohyuddin \&Khalil, 2016; Özerem, 2012; Rakes, 2010). This shows that research about misconceptions and mistakes in geometry is very important. When the teacher is able to understand the reason behind the misconception, it can be corrected by challenging or contrasting it with the right conception (misconceptions in geometry). Teachers need to be able to analyze errors and evaluate alternative ideas, anticipate learners' errors and common misconceptions, and be able to interpret students' incomplete thinking (Makhubele, Nkhoma, \& Luneta, (2015)).

Geometry has been widely recognized as one of the most difficult topics, which leads to learning difficulties worldwide. In Indonesia, students' performance on geometry is an important issue. This is in accordance with the reports of low geometry test results in TIMMS in 2007 and 2015. More specifically, students in Indonesia experienced a low achievement in the concept of conic sections. This was seen from students who were less enthusiastic in learning and had difficulty in solving the problems, besides teachers who also had difficulty in teaching the concept because it was not in the syllabus for 10 years and reappeared in the 2013 curriculum (Sari, 2016). The result of the National Examination of mathematics for the year 2013/2014 showed a low understanding of students on the concept of conics (Qudtsi, Setiawan, \& Lestari, 2015). Second-semester students at the university also did not understand the concept of conics in analytical geometry lectures (Purniati \& Sudihartinih, 2015).

According to Harper (2010), mistake, blunder, error, and slip refer to deviations from right, accuracy, correctness, or truth. Confrey has described that mistakes occur mainly because students have difficulty in understanding instruction from teachers or difficulty in understanding the concept (Luneta, 2015). Luneta (2015) defined error as 'a simple phenomenon of difficulty encountered by students during the learning experience'. Clements and Battista pointed out the reasons for students' misconceptions about the concept of geometry: students do not understand concepts adequately, they overly generalize specific rules about geometric expression, they mostly learn by rote, and they cannot understand concepts (Biber, Tuna, and Korkmaz, 2013). Spooner stated the difference between 'misunderstanding' and 'mistake' because they have similarities about the incorrect results of the answer. Other than that, the error may be due to misunderstandings, carelessness, problems in reading or interpreting questions, and lack of knowledge about numbers (Mohyuddin \& Khalil, 2016).

A Closer Look at Indonesian Students' Performance In Geometry
Figure 1 is a problem of the geometry in the 2015 TIMSS study. The result showed that only $21 \%$ of Indonesian participants answered correctly, while the international participants who answered correctly was averagely 58\% (Mullis et al., 2015).

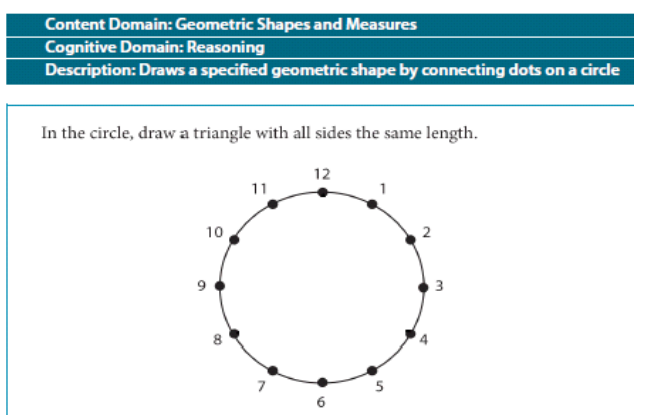

Figure 1 The Problem of the TIMSS Study

These results indicated a low understanding of Indonesian students on the concept of conics. In the 2013 curriculum for the eleventh grade, the first semester of the mathematical subject includes polynomial, conics, circle, and statistics. Here are the results of the research of Sari (2016).

Table 1. Grade Points of Eleventh Grade for Mathematics

\begin{tabular}{lcc}
\hline Concept & $\begin{array}{l}\text { Grade Point } \\
\text { Average }\end{array}$ & $\begin{array}{l}\text { Minimum } \\
\text { Criterion of } \\
\text { Mastery Learning }\end{array}$ \\
\hline Polynomial & 89.79 & 75 \\
Conics & 71.34 & 75 \\
Circle & 88.83 & 75 \\
Statistics & 85.37 & 75 \\
\hline
\end{tabular}

The average student achievement on the conic concept was 71.34. The grade point was below the ' Minimum Criterion of Mastery Learning' and was the lowest point compared to the points of other concepts. This proved the low understanding of students about the conic section concept. For example, students had difficulty in identifying parabola, ellipse, or hyperbola equation. Sari (2016) also conducted an interview with one of the eleventh-grade mathematics teachers in Indonesia. It was found that students were not able to solve problem involving conics because the students had low intuition in doing the questions, did not want to ask and try to solve practice problems, difficulty in memorizing the formula.

Based on the previous descriptions, it can be seen that there have not yet been identified mistakes and misconceptions in conic sections, so the purpose of this research is to know the level of geometric thinking, mistakes, and the misconceptions of students on the concept of conics. The description of the level of geometry, mistakes, and misconceptions of students on the concept of conics will help lecturers in making teaching materials and manipulatives to 
improve students' understanding so that students can follow the next lecture, for example, calculus.

\section{METHOD}

To answer the research question, we conducted an explorative study by giving an individual written test on the concept of conic in analytical geometry course. Analytical geometry course must be followed by students in the second semester. It includes 3-credit course of expertise. In analytical geometry course, it is studied the coordinate system, the equation of the straight line, circle, conics, the point in space, the plane, the straight line in space, the surfaces, and the curves. After the test, then interviews with students were conducted.

\section{Sample}

Participants of this study were 93 students at a university in Indonesia. In the first class, there were 46 students (6 males and 40 females). In the second class, there were 47 students (13 males and 34 female). The reason for choosing two-class samples was that each class only did three questions so that students could focus on it. These students were second-semester students at the Department of Mathematics Education. They were fresh graduate from Senior High School and aged about 18 years old. The students were currently studying analytical geometry on the conics concept.

\section{Data Collection}

Students were asked to write the answers on the paper that had been provided and then they were interviewed. Odd-numbered questions (1, 3, and 5) were given to the first class, while even-numbered problems $(2,4$, and 6$)$ were given to the second class. The time available for the test was 70 minutes. The tests were done individually and tests were given to both classes at the same time. The test was given after they learned the conics concept. During the course, the student was not allowed to use calculator. Problems were compiled by the team of researchers (lecturers of analytical geometry courses), who then made the answer key in order to predict the time required for students to complete it. Here were test questions.

1. Find a simple equation of the parabola passing through the point $(-1,5)$.

2. Simple equation of the parabola $4 y^{2}-32 x=0$. Identify the vertex, focus, endpoints of the latus rectum, and directrix, and sketch the parabola.

3. a set of points that have the property that the sum of their distances to the two foci in $(0,-1)$ and $(0,1)$ is 4 . Find an equation of the set.

4. Prove that the length of the latus rectum of an ellipse is equal to $2 a\left(1-e^{2}\right)$.

5. Find an equation of the hyperbola whose asymptote is $y=4 x, c=7$, and foci are on the $x$ axis.
6. Select the focus at $( \pm c, 0)$ and derive the theorem on hyperbole from the property that the set of points that differ from the two foci is $2 a$.

Students took a break after completing the test while we selected six students who experienced mistakes and misconceptions for interviews. Students were interviewed one by one by asking them to explain again how to work on the test paper and the interviews were recorded on video. The first interview was conducted on the wrong student at question number 1 , while the other students rested. Interviews continued until the sixth student who experienced a test error.

\section{Data Analysis}

Results of student work from both classes were corrected by researchers by using the assessment rubric. Further, the results were analyzed and grouped into the correct answer and incorrect answer. After that group at the level of geometry thinking. The incorrect answers were grouped into the types of mistakes. Meanwhile, the recorded interviews were transcribed for data analysis.

\section{The van Hiele Levels of Geometric Thinking}

According to van Hiele's theory (Usiskin, 1982), there are five levels of understanding of geometry:

1. Level 1 (recognition). Students can name the plane and recognize the shape completely (or can differentiate square and rectangle).

2. Level 2 (analysis). Students can identify the properties of polygons.

3. Level 3 (order). Students are logically able to sort two-dimensional shape and connect it, but unable to operate until the mathematical system.

4. Level 4 (deduction). Students understand significantly from the deduction and the role of postulate, theorem, and proof. (Proof can be written with understanding).

5. Level 5 (rigor). Students understand the need for rigor and proficiency to make abstract deductions. (Non-Euclidean geometry is understandable).

Originally, van Hieles numbered these levels from 0 to 4 , not 1 to 5 . The properties in the levels are as follows:

1. Property 1: fixed sequence. Students cannot be at a van Hiele level without passing the previous level.

2. Property 2: adjacency. at each level of thought what was intrinsic in the preceding level becomes extrinsic in the current level.

3. Property 3: distinction. Each level has its own linguistic symbols and its own network linking the symbols.

4. Property 4: separation. Two persons who reason at different level cannot understand each other.

The students' mistakes in problem-solving are classified into several categories. According to Makhubele, Nkhoma, and Luneta (2015), error 
categories were divided into three categories, i.e., err1, err2, and err3. Err1 (Slip) is a small mistake that is made because students are in a hurry. Err2 (conceptual error) is the lack of knowledge about concepts caused by inadequate mastery of basic facts, concepts, and skills. Err3 (procedural error) is when students know the concept, but cannot apply it to solve the problem. The following is classification of error categories according to Makhubele, Nkhoma, and Luneta (2015).

Table 2. Classification of Student's Errors

\begin{tabular}{|c|c|c|}
\hline Category & Error & Description \\
\hline Err1 & Slip & $\begin{array}{l}\text { Errors, small mistakes made } \\
\text { because students are in a } \\
\text { hurry. }\end{array}$ \\
\hline Err2 & $\begin{array}{l}\text { Conceptual } \\
\text { error }\end{array}$ & $\begin{array}{l}\text { Lack of knowledge about } \\
\text { concepts caused by } \\
\text { inadequate mastery of basic } \\
\text { facts, concepts, and skills. }\end{array}$ \\
\hline Err3 & $\begin{array}{l}\text { Procedural } \\
\text { error }\end{array}$ & $\begin{array}{l}\text { The student knows the } \\
\text { concept but cannot apply it to } \\
\text { solve the problem. They } \\
\text { apply the procedure without } \\
\text { really knowing what is being } \\
\text { done. }\end{array}$ \\
\hline
\end{tabular}

\section{RESULTS AND DISCUSSION}

Here are presented the number of students who answered correctly and incorrectly on each numbered question.

Table 3. Evaluation of Student Solutions

\begin{tabular}{ccccccc}
\hline Question & 1 & 2 & 3 & 4 & 5 & 6 \\
\hline $\begin{array}{c}\text { Correct } \\
(\%)\end{array}$ & 4.4 & 44.7 & 56.5 & 44.7 & 47.8 & 42.6 \\
$\begin{array}{c}\text { Incorrect } \\
(\%)\end{array}$ & 95.6 & 55.3 & 43.5 & 55.3 & 52.2 & 57.4 \\
$\begin{array}{c}\text { Number } \\
\text { of }\end{array}$ & 46 & 47 & 46 & 47 & 46 & 47 \\
students & & & & & & \\
\hline
\end{tabular}

Based on Table 3, it is known that the percentages of students who answered incorrectly on problems number $1,2,3,4,5$, and 6 respectively were $95.6 \%, 55.3 \%$, 43.5\%, 55.3\% 52.2\%, and $57.4 \%$. The biggest incorrect answer was at number 1 because it was an open-ended problem, so students had to solve the problem with more than one solution. However, in reality, students were not familiar with this open-ended problem. The number of students who are wrong in other numbers tends to be around $50 \%$ of the number of students. Furthermore, the wrong answers were grouped in the following classifications: err1, err2, and err3.

Table 4. Categories of Errors

\begin{tabular}{|c|c|c|c|c|c|c|c|}
\hline Category & \multicolumn{6}{|c|}{ Question Number } & \multirow{2}{*}{ Total } \\
\cline { 2 - 7 } & 1 & 2 & 3 & 4 & 5 & 6 & \\
\hline Err1 & 0 & 3 & 2 & 2 & 0 & 3 & 10 \\
\hline Err2 & 40 & 20 & 20 & 23 & 20 & 29 & 152 \\
\hline Err3 & 3 & 1 & 2 & 0 & 8 & 0 & 14 \\
\hline
\end{tabular}

Based on Table 4, the numbers of students who made error categories of err1 err2, and err3 on question number 1 were 0,40 and 3 students, respectively. On question number 2, 3 students, 20 students, and 1 student made error categories of err1, err2, and err3, respectively. On number 3, there were 2, 20 and 2 students who made error categories of err1, err2, and err3. On question number 4, 2 students, 23 students, and 0 students made errors of err1, err2, and err3. On the number 5, err1, err2, err3 were made by 0,20 and 8 students. On the problem number 6, 3 students, 29 students, and 0 students made errors. Meanwhile, the numbers of students who made errors from the number 1 to 6 were 10,152, and 14 students. In summary, most students made error category of err2, which was conceptual error.

By observing the students' written work, it was difficult to determine the mistakes that the student made. The following interview transcript shed new light on the students' thinking.

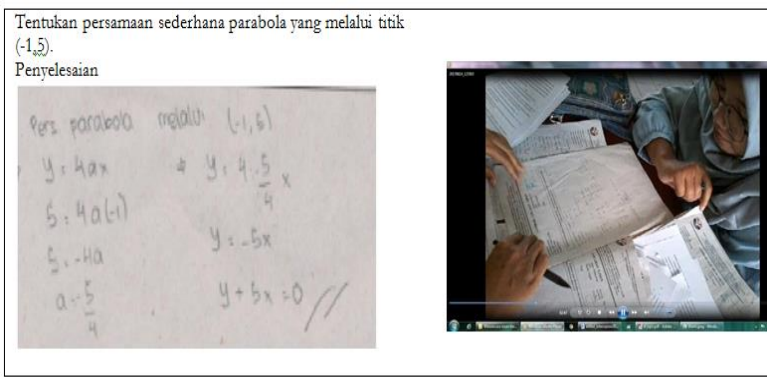

Figure 2. Student Interview on Task 1

$\mathrm{I}$ : Why is the answer like this?

$\mathrm{S}$ : Because the equation contains $\mathrm{x}$ and $\mathrm{y}$.

$\mathrm{I}$ : What is the parabola equation?

$\mathrm{S}$ : Hmmm. What is it?

$\mathrm{I}$ : What is the parabola equation?

S: Because initially, it is (while writing), for example $f(a, 0), x=-a, x-a=0$

$\mathrm{I}$ : Next, why is it $\mathrm{y}=4 \mathrm{x}$ ?

$S$ : This is it at first, then $y=4 x$ because it is through ($1,5)$ so it was substituted into $y=4 x$.

$\mathrm{I}: \mathrm{y}=4 \mathrm{ax}$, what equation is it?

S: Parabola equation.

I: Is $y=4 x$ really parabola equation?

S: $\mathrm{y}^{2}$, it should be $\mathrm{y}^{2}=4 \mathrm{ax}$, right, ma'am?

$\mathrm{I}$ Y Yes. [The equation is] so wrong from the beginning?

S: Yes, ma'am.

Based on the answers and interviews, it was known that students directly entered the point on the wrong parabola equation. Previously, students should draw the possibility of parabola images. So, it can be concluded that the students could not find two possibilities of simple parabola equations through a point. Because the students could not determine two possibilities of the parabola according to the graph, then the equation had to be determined. 
The following is interview of task 2 on the student's thinking, and the answers are in Figure 3.

$\mathrm{I}:$ Why is this the answer?

S: Because the simple equation is like that.

I: Oh. Then, why is the vertex at $(2,0)$ ?

S: Because its vertex is at $(a, 0)$. It's a simple equation.

I: Then, why is the focus at $(0,0)$ ?

$S$ : If that's the case, then the focus point is there.

$\mathrm{I}$ : What is the latus rectum?

$\mathrm{S}$ : The line through the vertex.

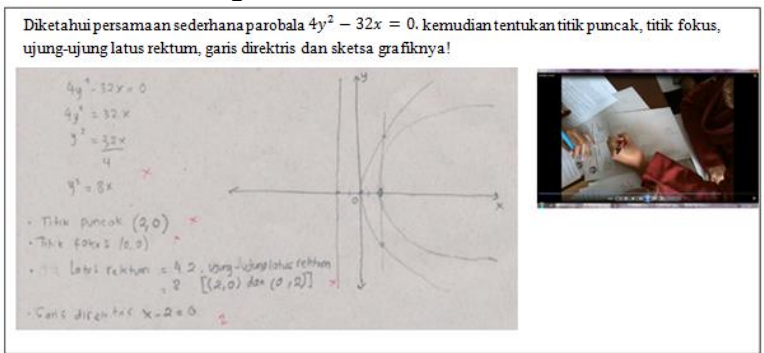

Figure 3. Student Interview on Task 2

According to the answers and interviews on question number 2 , students could not determine the vertex, the end of the latus rectum, and directrix, and could not draw a simple parabola equation. Because the student did not understand that a simple parabola equation has a vertex at $(0,0)$, that causes them to incorrectly determine the focus and the directrix. In addition, the students also did not understand the definition of the latus rectum so students could not draw a simple parabola equation. It can be concluded that the students could not solve the problem because they did not understand the definition of a simple parabola equation.

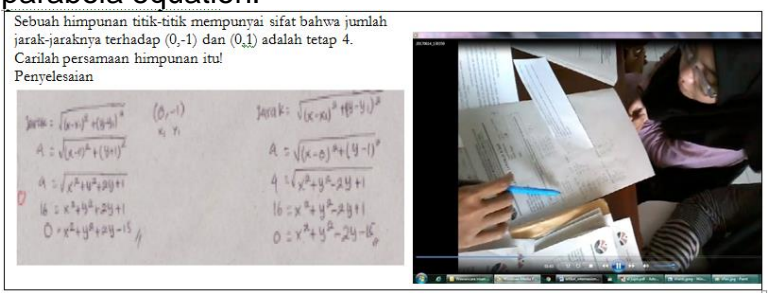

Figure 4. Student Interview on Task 3

I: Why is this the answer?

$\mathrm{S}$ : The sum of distances to $(0,-1)$ and $(0,1)$ is constant, so the distances of two point formula was used, then derived to completion.

I: But the sum of distance, if this is the distance between two points. So what's this about?

S: (Silence)

I: Parabola, ellipse, or hyperbola?

S: Parabola.

Based on the answers and interviews of students, it is known that students could not determine the conics equation because the students were wrong in using the formula of distance of two points. In addition, the students did not understand that the problem could be solved using the theorem on the ellipse that is "the sum of the distances to two fixed points is constant" (Each point on the ellipse has the property that the distance of the point on the ellipse to foci is equal to the length of the major axis). From the problem, we got the value of $a$ and $c$. In the ellipse, the equation $a^{2}=b^{2}+c^{2}$ should be applied so that $b$ can be identified. Furthermore, a simple ellipse equation can be made. So, it can be concluded that students could not solve the problem because the students were wrong in using the formula of distance between two points or in other words, the students did not understand the ellipse theorem.

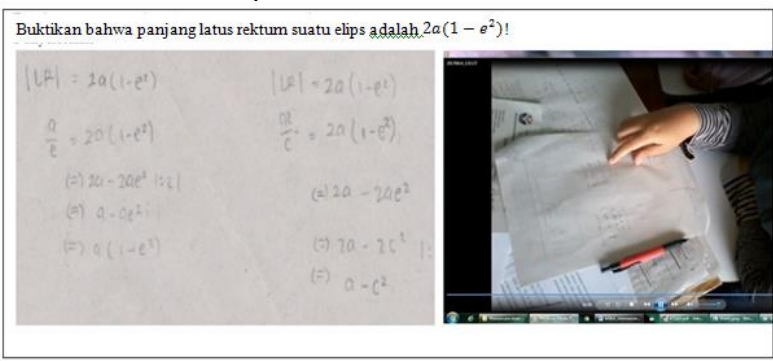

Figure 5. Student Interview on Task 4

I: Why is this the answer?

S: I think the length of the latus rectum is $\frac{a}{a}$. Then, ae

is replaced with $c$.

$\mathrm{I}$ : Is it proven?

S: [l am] confused, Ma'am.

The analysis of the answers and interviews obtained a result that students misunderstood the problem that should be proven but instead write from what should be proven. To prove this, students should know that the length of the latus rectum is $\frac{2 b^{2}}{a}$ and by using the properties of the ellipse $b^{2}=a^{2}-c^{2}$ and replacing $c=a e$, it can be proven that the length of the latus rectum is $2 \mathrm{a}\left(1-\mathrm{e}^{2}\right)$. So, it can be concluded that students could not solve the problem because students have not understood the length of the latus rectum and the properties on the ellipse.

The following is interview regarding task 5 .

$\mathrm{I}$ : Why is this the answer?

S: From asymptote $y=4 x$, it was obtained $b=4$ and $a=1$.

I: Next?

S: Because of the simple equation of hyperbola, so the values of $a$ and $b$ obtained are substituted into the equation. 


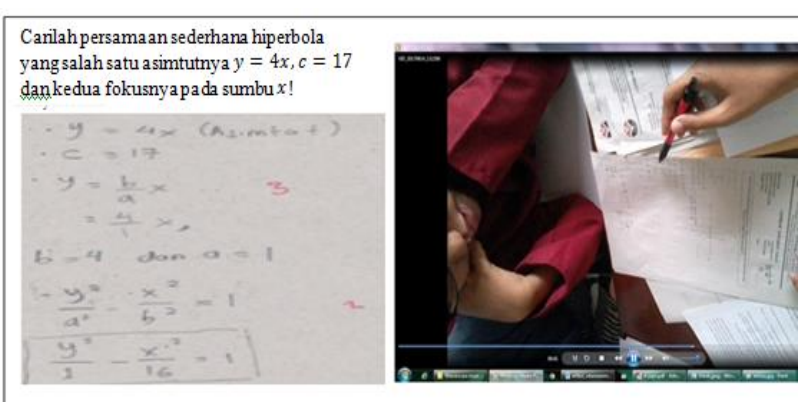

Figure 6. Student Interview on Task 5

Based on the answers and interviews with the students, it was found that the students were correct in determining the asymptote equation, but wrong in determining the value of $a$ and $b$. In addition, students mistakenly wrote simple hyperbola equations whose focus is on the $y$-axis, while the focus should lie on the $x$-axis. In conclusion, the students incorrectly solved the problem because the student could not determine the simple hyperbola equation in which one of the asymptotes and the center point were known and both foci were on the $x$-axis. This was because (a) the students could not know the relationship between $a$ and $b$ based on asymptotes, while (b) could not determine the relationship of $c^{2}=a^{2}+b^{2}$.

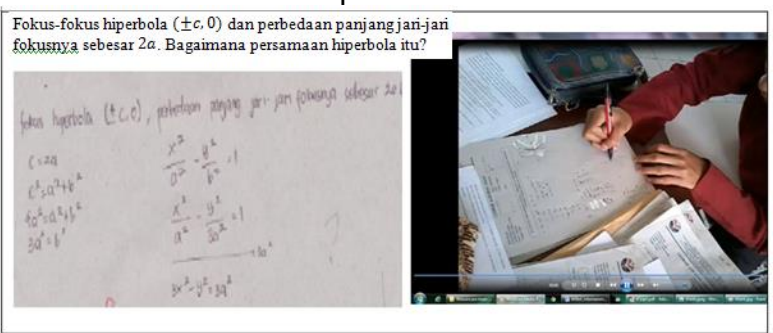

Figure 7. Student Interview on Task 6

I: Why did you do it this way?

$S$ : I do not understand what the ratio of the length of the radius of focus is.

$\mathrm{I}$ : Does the ratio with a difference equal?

S: [It is] the same.

I: This is the theorem on the hyperbola. So, the difference between the two radii of focus is fixed. Do you know the radius of focus?

S: No.

I: Try to sketch the ellipse. Show the focus.

S: Ellipse?

I: [You] may use the coordinate axis.

S: Hmmm... (drawing ellipse)

$\mathrm{I}$ : Yes, it can be on the $x$-axis.

S: Like this?

I: Where's the focus? Close enough.

S: Like this?

I: Wrong. Create one radius of focus.

S: Here?
I: It's up to you.

S: (Making one radius of focus) Like this?

I: Yes. Where else [can you create radius of focus]?

By going through the same point.

S: This? (Pointing to the focal point that has been drawn earlier)

I: No. The point on the ellipse.

S: (Pointing to the point on the ellipse)

I: Connect to other focus.

S: (Making the radius of focus) Like this?

$\mathrm{I}$ : Yes, that's the sum of the distance. When it comes to hyperbola, the difference is in distance.

S: What about this?

I: It should be derived. Can it be a written distance difference?

S: (Shaking head).

According to the answers and interviews, the student could not determine the equation of 'difference of radius of focus $2 \mathrm{a}$ '. To solve it, students should use the formula of distance of two points. Furthermore, to derive a simple hyperbolic equation, a good algebraic ability is required. Thus, the students could not determine the hyperbola equations. The focus and the difference between the lengths of radius of the focus were known because they could not use the distance formula.

Based on the results of answers and interviews, students obtained the following types of misconceptions.

Table 5. Types of Misconceptions

Question Type of Misconception

\section{Number}

a. The students cannot determine two possible simple parabola equations through a point, because they cannot draw those parabolas and/or cannot complete further from the definition of a parabola that has been determined by them.

b. The students can only determine one possible parabola equation.

2 The students cannot determine (a) the vertex (b) the foci (c) the ends of the latus rectum (d) the directrix, and (e) the graph of a simple parabola equation.

$3 \quad$ The students cannot determine the conic equation if the sum of distances to two fixed-points is constant (a) since they do not know that in ellipse $a^{2}=b^{2}+c^{2}$ and/or cannot determine the ellipse equation whose focus is known.

$4 \quad$ The students cannot prove that the length of the latus rectum an ellipse because they cannot determine (a) $a^{2}=b^{2}+c^{2}$, and (b) $\mathrm{c}=\mathrm{ae}$. 
5 The students cannot determine simple hyperbola equation whose one of the asymptotes and the vertex are known and both foci are on the x-axis. This is due to (a) inability to know the relationship between $a$ and $b$ based on their asymptotes and (b) inability to determine relationships of $c^{2}=a^{2}+b^{2}$

6 The students cannot determine simple hyperbola equation of the foci while the difference between the lengths of the radius of the foci is known. It is because (a) the students cannot determine the distance between two points and (b) it is due to the algebraic mistake.

The percentage of students who experienced the first error type was $95.6 \%$. They could not determine two possibilities of simple parabola equations through a point because they could not draw parabola and/or could not complete further from the definition of hyperbola, which had been determined by the student themselves. The second type of error was that students could not determine (a) the vertex (b) the foci (c) the ends of the latus rectum (d) the directrix, and (e) the graph of a simple parabola equation. The third type of error was experienced by $43.5 \%$ of the total number of students. They could not determine the conic equation if the sum of distances to two fixed points is constant because they (a) did not know that in the ellipse $a^{2}=b^{2}+c^{2}$ and/or (b) they could not determine the known ellipse equation. The fourth type of error was that students could not prove that the length of the latus rectum of an ellipse is $2 a\left(1-e^{2}\right)$ because they could not determine (a) $a^{2}=b^{2}+c^{2}$, and (b) $\mathrm{c}=a e$. The fifth type of error was experienced by $52.2 \%$ of the students. They could not determine simple hyperbola equation whose one of the asymptotes and the vertex are known and whose foci are on the $x$-axis, since they (a) could not know the relationships between $a$ and $b$ based on the asymptotes and they (b) could not determine the relationship of $c^{2}=a^{2}+b^{2}$. The sixth type of error occurred in $57.4 \%$ of the students. They could not determine the hyperbola equation of foci when the difference between the lengths of the focus radius was known because (a) they could not determine the distance between two points and (b) there was algebraic mistake.

Such misconceptions occur because of misconceptions in other areas of mathematics. One cause of misconception in geometry is an algebraic misconception. If there is algebraic misconception, then there will be misconception in geometry (Rakes, 2010). In addition, analytical geometry is a geometry that is solved using algebra. Here is an example of algebraic misconception.

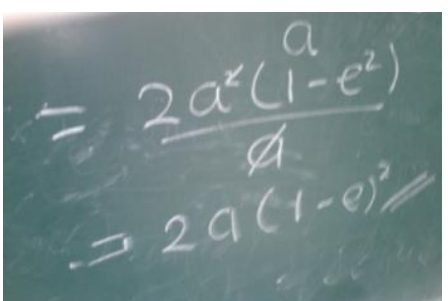

Figure 8. The algebraic misconception that the students had when answering conic questions

In Figure 8, the student exhibited a misconception on $\left(1-\mathrm{e}^{2}\right)$ to $(1-\mathrm{e})^{2}$. Misconception that was similar to this was exhibited several times by different students.

Based on the answer and interviews of the students on item number 1 , it appears that the main cause of the mistake was the visualization, which is the first level at the van Hiele levels of geometry thinking. At this level, students can name and recognize conic, but do not look at the concept of conic sections as a whole. An important point of van Hiele levels is to explain the development of geometry thinking in five related levels. Each of these five levels defines the process of geometry thinking used. This level determines how they think and what geometry ideas they are facing, not how much knowledge they have (Van de Walle, Karp, \& Bay-Williams, 2013).

According to the student work on questions 2, 3, 4,5 , and 6 (similar questions that required the use of knowledge of a similar solution), it appears that the main cause of the error was about analysis, which is the second level of van Hiele levels of geometry thinking. At this level, the student can recognize a geometric shape based on its properties but cannot recognize the relationships between classes of figures. According to findings and research results, students preferred to learn by rote when they failed to understand the properties of geometry. However, the knowledge gained by memorization cannot last long. They can forget it in a short time. This creates a problem for teaching geometry in which subjects are closely related to each other (Biber, Tuna, \& Korkmaz, 2013). Students should learn by finding and constructing their own concepts so when they forget, they can reconstruct the concept. Based on these findings, there were still students who were at level 1 and level 2. This was in accordance with Sudihartinih and Mulyana (2014) who conducted research on seventh semester students. It was found that the numbers of students whose levels of geometry thinking were at level 1 , level 2 , level 3 , level 4 , and level 5 were as many as 7 students, 8 students, 11 students, 2 students, and 0 , respectively. Mistakes and misconceptions of student in understanding the concept of conic need to be reduced so changes in the teaching of geometry are necessary in order to take care of students' difficulties (Smith, 1940). Changes in geometry learning are also needed to improve students' learning motivation. Higher self-confidence in mathematics and higher motivation to learn 
mathematics are associated with reduced misconception and errors (Rakes, 2010). The preservice teachers' misconceptions were multidimensional, whereas pre-service teachers' knowledge in this area was narrow that pre-service teachers interpreted students' errors from only one or two perspectives (Kim, 2002). One of the ways to improve students' understanding is by using learning media, both in the form of geometry software and manipulatives. This corresponds to the report of study conducted by Sari (2016) that one way to improve students' understanding of the concept of conic was to use manipulatives. Purniati and Sudihartinih (2015) have designed manipulatives of conic concept based on theorems and definitions. In addition, the manipulatives by definition have also been designed by Sudihartinih and Purniati (2016). Both tools have been certified with IPR (Intellectual Property Rights) in Indonesia. Furthermore, open-ended problems are needed in learning, so that students are familiar with problem that has many solutions. The open-ended approach begins with presenting incomplete problem, i.e., problem that is formulated and has more than one way to answer and more than one correct answer (Shimada, 1997). Further research is also much needed because there are many student errors in solving geometry problems. The errors are both errors in geometric concepts and errors in algebra.

\section{CONCLUSION}

The students who answered incorrectly on questions number $1,2,3,4,5$, and 6 were $95.6 \%$, $55.3 \%, \quad 43.5 \%, \quad 55.3 \%, \quad 52.2 \%$, and $57.4 \%$, respectively. Students' misconceptions in learning conic were (1) inability to determine the two possible simple equations, (2) inability to determine the description of a simple parabola equation, (3) inability to determine the conics equation, (4) inability to prove the length of the latus rectum of an ellipse, (5) inability to determine a simple equation when an asymptote of hyperbola and its vertices point are known, and (6) inability to determine the hyperbola equations of focus when the difference between the lengths of the radius of the focus is known. Therefore, further research is needed to reduce the mistakes and misconceptions of students in learning analytical geometry.

\section{ACKNOWLEDGMENT}

We would like to thank students of the Department of Mathematics Education and the Directorate General of the Ministry of Research, Technology and Higher Education of the Republic of Indonesia for their support of this study.

\section{REFERENCES}

Ayoub, A. B. (2007). The director circle of a central conic section. Mathematics and Computer Education 41(2), 136-142.
Biber, Ç., Tuna, A., Korkmaz, S. (2013). The mistakes and the misconceptions of the eighth-grade students on the subject of angles. European Journal of Science and Mathematics Education, 1(2), 50-59.

Buczkowske, L. (1994). Understanding Algebraic Concepts and Conics. The Mathematics Teacher 87(4), 297-298.

Chernysheva, L. Y., Firsov, V. V., \& Teljakovskii, S. A. (1986). Teaching geometry in the USSR. In R. Morris (Ed), Studies in mathematics education (Vol. 5, pp. 97-106). United Kingdom: Imprimerie des Presses Universitaires de France.

Gal, H., \&Linchevski, L. (2010). To see or not to see: Analyzing difficulties in geometry from the perspective of visual perception. Educational Studies in Mathematics, 74(2), 163-183. https://doi.org/10.1007/s10649-010-9232-y

Harper, D. (2010). Online etymology dictionary. Retrieved November 29, 2017, http://www.dictionary.com/browse/mistake?s=t

Jones, K. (2002), Issues in the teaching and learning of geometry. In Haggarty, L. (Ed), Aspects of teaching secondary mathematics: Perspectives on practice (pp. 121-139). London, UK: Routledge Falmer.

Kim, J. S. (2002). Preservice teachers' knowledge of content and students in geometry (Unpublished Dissertation). The University of Georgia, Georgia.

Kung, S. H. (2003). Finding the tangent to a conic section without calculus. The College Mathematics Journal 34(5), 394-395. https://doi.org/10.2307/3595824

Ladd, C. (1992). Concepts in mathematics: Conic sections. The Mathematics Teacher 85(9) 767768.

Luneta, K. (2015). Understanding students' misconceptions: An analysis of final grade 12 examination questions in geometry. Pythagoras, 36(1), 1-11. https://doi.org/10.4102/pythagoras.v36i1.261

Makhubele, Y., Nkhoma, P., \& Luneta, K. (2015). Errors displayed by learners in the learning of grade 11 geometry. Proceedings of ISTE International Conference on Mathematics, Science And Technology Education, 26-44.

Mathematics Standards Study Group. (2004). What is important in school mathematics. Retrieved from http://www.ams.sunysb.edu/ tucker/LeadEssay.p df

Mohyuddin, R. G., \& Khalil, U. (2016). Misconceptions of students in learning mathematics at primary level. Bulletin of Education and Research 38(1), 133-162.

Mullis, I. V. S., Martin, M. O., Foy, P., \& Hooper, M. (2015). TIMMS 2015 International result in mathematics. IEA: TIMSS \& PIRLS, Boston College. 
Nhi, D. M., Tinh, T. T., \& Phuong, P. M. (2014). Some new identities on the conic sections. Journal of Science and Arts, 3(28), 199-210.

Özerem, A. (2012). Misconceptions in geometry and suggested solutions for seventh grade students. International Journal of New Trends in Arts, Sports \& Science Education 1(4), 23-35. https://doi.org/10.1016/j.sbspro.2012.09.557

Peng-yee, L., Chong-keang, L. (1986). Geometry in Southeast Asia. Studies in Mathematics Education Teaching of Geometry. In R. Morris (Ed), Studies in mathematics education (pp. 97106). London, UK: Imprimerie des Presses Universitaires de France.

Purniati, T., \& Sudihartinih, E. (2015). Visual aids in analytical geometry course in conics concept. Proceedings of International Seminar on Mathematics, Science and Computer Science Education.

Qudtsi, Setiawan, T. B., \& Lestari, N.D.S. (2015). Proses Pembelajaran Irisan Kerucut pada SMKN dengan Daya Serap Siswa Rendah Terbanyak di Jember pada Ujian Nasional Matematika Tahun 2013/2014 [Learning Process of Conics on Students Low Absorption Ability in SMKN Jember at the National Examination Year 2013/2014]. Artikel IImiah Mahasiswa, 1(1), 1-6.

Rakes, C. R. (2010). Misconceptions in rational numbers, probability, algebra, and geometry. Electronic Theses and Dissertations. Paper 1176. ThinkIR: Dissertations of The University of Louisville's Institutional Repository, US.

Ramlan, A. M. (2016). The effect of van Hiele Learning model toward geometric reasoning ability based on the self-efficacy of senior high school students. Journal of Mathematics Education 1(2) 63-72.

Sari, P. P. (2016). Analisis kasus rendahnya prestasi belajar matematika siswa pada materi irisan kerucut dan solusi pemecahannya di kelas XI IA 2 SMAIT Nur Hidayah [Analysis of Low Achievement of Student Mathematics Learning on Conics and Solution in Class XI IA 2 SMAIT NUR HIDAYAH]. Proceedings at the National Conference on Mathematics and Learning Research di UNS, Indonesia.

Smith, R. R. (1940). Three major difficulties in the learning of demonstrative geometry. The Mathematics Teacher, 33(3), 99-134.

Sudihartinih, E. \& Purniati, T. (2016). Alat peraga konsep irisan kerucut. Proceedings at the National Mathematics Seminar at UNPAR, Indonesia.

Sudihartinih, E., \& Mulyana, E. (2014). Perkuliahan geometri transformasi dengan pendekatan kontruktivisme untuk meningkatkan level berpikir geometri van Hiele [Geometry Transformation Lecture with Constructivism Approach to Increase Thinking Level of Van Hiele Geometry]. Jurnal Pendidikan Matematika Sigma Didatika, 3(1) 12-16.
Usiskin, Z. (1982). Van Hiele level and achievement in secondary school geometry. Reports of Research of Department of Education at the University of Chicago. Washington, DC, USA: National Inst. of Education (ED).

Van de Walle, J. A., Karp, K.S., Bay-Williams, J. M. (2013). Elementary and middle school mathematics (eighth edition). New Jersey, US: Pearson Education, Inc.

Wood, D. W. (2012). "Mathesis of the mind": A study of fichte's wissenschaftslehre and geometry. Amsterdam, The Netherlands: Rodopi.

Shimada, S. 1997. The significance of an open-ended approach. In J. P. Becker \& S. Shimada (Ed.) The open-ended approach: $A$ new proposal for teaching mathematics. Virginia, US: National Council of Teachers of Mathematics.

van Hiele, P. M. (1984), A child's thought and geometry. In D. Fuys, D. Geddes and R.W. Tischler (Eds.) (1959/1985) English translation of selected writings of Dina van HieleGeldof and Pierre M. van Hiele, (pp. 243-252). Brooklyn, US: Brooklyn College. 